\title{
Developing Cerebral Venous infarct presenting with seizure occurring after lumbar drain placement following Trans-sphenoidal Surgery of Cushing's disease: Review of literature
}

Sir,

Cerebral venous thrombosis (CVT) can have varied clinical presentations and more commoner causes include trauma, dehydration, pregnancy, mastoiditis, neoplasms and hematological abnormality, leukemia, and thrombocythemia. However, very rarely, venous thrombosis is reported in Cushing's syndrome. ${ }^{[1,2]}$

Trans-sphenoidal surgery remains the surgical approach of choice for the management of pituitary adenoma.
However, trans-sphenoidal surgery may rarely be associated with cerebrospinal fluid (CSF) rhinorrhea, meningitis, pneumocephalus, and seizure. Lumbar drain placement in postoperative period following trans-sphenoidal surgery for CSF rhinorrhea is well accepted supporting measure in association with sellar floor reconstruction and sellar packing. ${ }^{[3]}$ Lumbar drain placement is rarely associated with complication and may vary from mild headache, fever to meningitis. However, till date, no such cases of the development of 
cerebral venous infarct due to the use of lumbar drain in CSF leak after trans-sphenoidal surgery for Cushing's disease is reported in the Western literature.

A 43-year-old female presented with complaints of progressive weight gain of about $35 \mathrm{~kg}$ and hirsutism for last 7 years. She also had polydipsia and polyurea, and on evaluation, diagnosed to have central diabetic insipidus for the last three years and associated with co-morbidities of Type-2 diabetes mellitus and hypertension, which were managed with regular oral medications under physician supervision. She was diagnosed to suffering with obstructive sleep apnea for last 10 years. She had two episodes of deep venous thrombosis involving lower limbs, which was managed conservatively in the years 2004 and 2009. However, there were no associated visual complaints, amenorrhea. On evaluation at admission revealed morbid obesity with weight of $115 \mathrm{~kg}$ with the presence of moon face, centripetal obesity, buffalo hump, and hirsutism and skin striae. Neurological evaluation showed visual acuity of $6 / 6$ without visual field defects bilaterally; however, the rest of examination was normal. Serum biochemistry revealed raised cortisol and adrenocorticotropic hormone (ACTH) levels and high evening salivary cortisol level and labeled as ACTH dependent Cushing's disease. She was further evaluated in detail for obstructive sleep apnea for the suitability of surgical procedure under general anesthesia. Hematological work up including the coagulation factors and autoimmune antibodies for hypercoagubale state was noncontributory. Contrast-enhanced magnetic resonance imaging (MRI) brain sagittal section revealed $1.5 \mathrm{~cm} \times 1.4 \mathrm{~cm}$ size pituitary macroadenoma in sellar-suprasellar location with intense enhancement [Figure 1]. She underwent MRI-based neuronavigation-guided sublabial trans-sphenoidal approach in Brainlab suit and complete excision of pituitary adenoma achieved as evidence on postoperative MRI scan [Figure 2]. Intraoperatively, CSF leak was noted which was managed with sellar floor reconstruction with fat, fascia, and glue. Lumbar drain was placed in postoperative period. In immediate postoperative period, her condition was stable with serum cortisol and ACTH level became normal, and there was also complete cessation of CSF rhinorrhea. Although she needed noninvasive continuous positive airway pressure (CPAP) ventilatory support for obstructive sleep apnea. She had episodes of diabetes insipidus in postoperative period which required desmopressin puff. On $4^{\text {th }}$ postoperative day, she had acute aggravation in severity of headache associated with one episode of generalized tonic clonic seizure. In postictal period, she developed left sided hemiparesis. Noncontrast computed tomography (CT) head revealed venous infarct in posterior frontal territory on right side [Figure 3]. She was managed conservatively

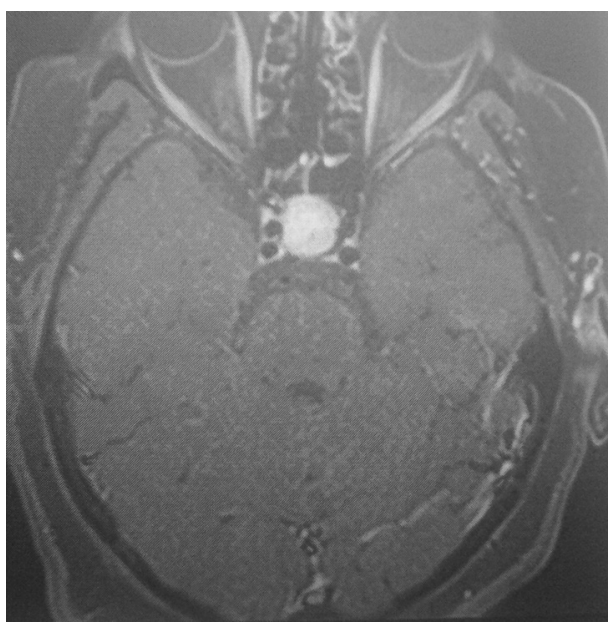

Figure 1: Magnetic resonance imaging brain, contrast enhanced scan saggital section image showing sellar - suprasellar mass, which is showing intense enhancement suggestive of pituitary adenoma

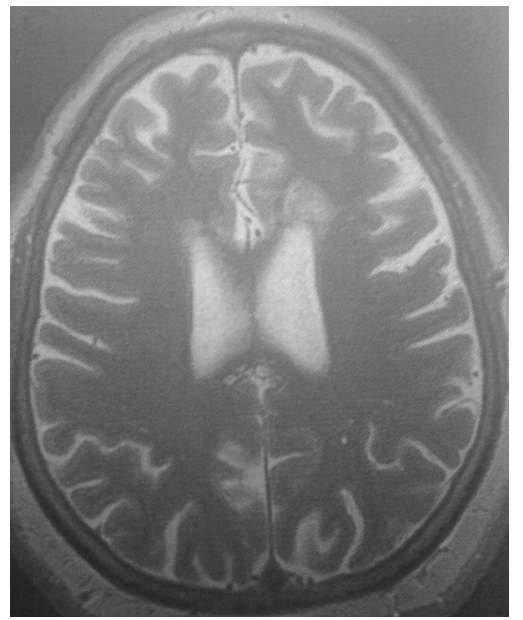

Figure 2: Intraoperative magnetic resonance imaging scan, axial section, T2-weighted image acquired at the end of surgery in the magnetic resonance imaging operation suit, higher section showing no evidence of developing infarct

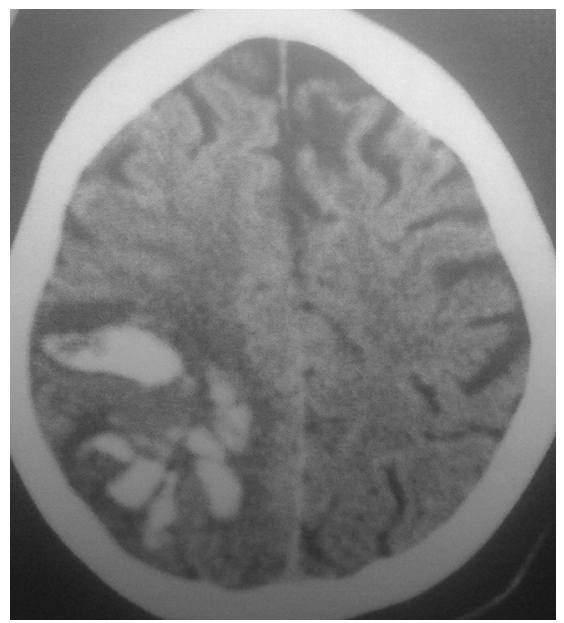

Figure 3: Computed tomography scan of head, on postoperative day 4 , showing presence of venous infarct in the right temporal and posterior frontal regions 
with cerebral decongestant and followed with repeat CT scan. Patient's condition improved initially and headache subsided and hemiparesis improved to $3 / 5$. As she was showing progressive improvement with conservative management, she developed sleep apnea episode in midnight associated with malfunction of CPAP ventilator along with myocardial infarction and succumbed to it.

Endogenous Cushing's disease occurring due to pituitary adenoma accounts for $8 \%-10 \%$ of all pituitary tumors and estimated incidence is about $0.7-2.4$ cases per million individuals per year. ${ }^{[3]}$ Cushing's disease is associated with high risk of morbidity and mortality due to associated multiple systemic as well as metabolic changes. ${ }^{[4]}$ Venous thromboembolic complications are rare but important and its incidence ranges from $0 \%$ to $5.6 \%{ }^{[5]}$ Hypercoagulable state is caused by alterations in fibrinolytic factors with increased levels of fibrinogen, plasminogen activating Factor 1, Factor VIII, IX, and vWF. ${ }^{[5]}$ However, CVT following trans-sphenoidal surgery of current case of Cushing's disease is first case reported in the western literature. CSF rhinorrhea occur in about $1.5 \%-4.2 \%$ cases undergoing trans-sphenoidal surgery, but constitute one of the serious complications, requiring and sellar floor reconstruction, packing of sella with fat, fascia, muscle, glue is usually carried out in the intraoperative period for management. In addition, CSF drainage with lumbar drain is also well accepted adjunct. Intracranial hypotension due to CSF over drainage leading to headache is the common which have specific orthostatic character and responds well to the bed rest and increasing hydration.

CVT is the rare pathological condition can have varied etiopathogenesis. Only a few cases of CVT are reported in the literature after lumbar puncture and intrathecal medication via lumbar puncture and rarely after the diagnostic lumbar puncture. Therapeutic lumbar drain CSF drainage causing lateral sinus thrombosis after spinal surgery for CSF leak reported by the Miglis and Levine, ${ }^{[6]}$ and the author postulated orthostatic intracranial hypotension causes acute dilation of cerebral veins leads to venous stasis and CVT. In the current case, lumbar drain was kept for 4 days, lead to intracranial hypotension, which might have led to venous stasis, and in addition, she also developed diabetic insipidus leading to the aggravation of intermittent hypovolemic states and above combinations might predisposed for the CVT development. However, Cushing's disease can also predisposed to thrombophillic state caused by hypercortisolism and may itself lead to intracranial venous thrombosis as reported in some of cases of Cushing's syndrome even without surgical intervention or placement of. ${ }^{[1]}$ The character of headache on the $4^{\text {th }}$ postoperative day changed to continuous in nature and aggravation of intensity to moderate severity. Hence, changing pattern and aggravation of headache intensity may provide clue to suspect the probability of onset of intracranial CVT development in patients kept on lumbar drain in situ.

\section{Financial support and sponsorship Nil.}

\section{Conflicts of interest}

There are no conflicts of interest.

Dattaraj Sawarkar, Guru Dutta Satyarthee, Pankaj Singh, Hitesh Gurjar, M. M. Singh, B. S. Sharma

Department of Neurosurgery, All India Institute of Medical Sciences, New Delhi, India

Address for correspondence: Dr. Guru Dutta Satyarthee, Department of Neurosurgery, Neurosciences Centre, All India Institute of Medical Sciences, Room No. 714, New Delhi - 110 029, India. E-mail: duttaguru2002@yahoo.com

\section{References}

1. Giorgetti A, Calloni MV, Freschi R, Mariani G, Perrone P, Secchi P, et al. Cerebral venous thrombosis after lumbar puncture and high steroid cycle in a patient with multiple sclerosis. J Headache Pain 2001;2:45-8.

2. Dlamini N, Billinghurst L, Kirkham FJ. Cerebral venous sinus (sinovenous) thrombosis in children. Neurosurg Clin N Am 2010;21:511-27.

3. Newell-Price J, Bertagna X, Grossman AB, Nieman LK. Cushing's syndrome. Lancet 2006;367:1605-17.

4. Manetti L, Bogazzi F, Giovannetti C, Raffaelli V, Genovesi M, Pellegrini G, et al. Changes in coagulation indexes and occurrence of venous thromboembolism in patients with Cushing's syndrome: Results from a prospective study before and after surgery. Eur J Endocrinol 2010;163:783-91.

5. Trementino L, Arnaldi G, Appolloni G, Daidone V, Scaroni C, Casonato A, et al. Coagulopathy in Cushing's syndrome. Neuroendocrinology 2010;92 Suppl 1:55-9.

6. Miglis MG, Levine DN. Intracranial venous thrombosis after placement of a lumbar drain. Neurocrit Care 2010;12:83-7.

This is an open access article distributed under the terms of the Creative Commons Attribution-NonCommercial-ShareAlike 3.0 License, which allows others to remix, tweak, and build upon the work non-commercially, as long as the author is credited and the new creations are licensed under the identical terms.

\begin{tabular}{|l|l|}
\hline \multicolumn{2}{|c|}{ Access this article online } \\
\hline Quick Response Code: & Website: \\
\hline & www.ruralneuropractice.com \\
\cline { 2 - 2 } & \\
\hline
\end{tabular}

How to cite this article: Sawarkar D, Satyarthee GD, Singh $P$, Gurjar H, Singh MM, Sharma BS. Developing cerebral venous infarct presenting with seizure occurring after lumbar drain placement following trans-sphenoidal surgery of cushing's disease: Review of literature. J Neurosci Rural Pract 2017;8:148-50. 